\title{
MODEL KECELAKAAN LALULINTAS BERDASARKAN KORELASI POPULASI, TINGKAT PEMAHAMAN PENGGUNA DAN TINGKAT PERTUMBUHAN KENDARAAN DI KOTA BESAR, SEDANG DAN KECIL SUMATERA BARAT
}

\author{
Cut Dona Kordelia ${ }^{1}$, Yossyafra ${ }^{2}$, Titi Kurniati ${ }^{3}$
}

\begin{abstract}
ABSTRAK
Sumatera Barat merupakan salah satu provinsi dengan jumlah kecelakaan cukup tinggi, dari data Badan Pusat Statistik (BPS) memperlihatkan bahwa peningkatan rata-rata kecelakaan mencapai angka $34.72 \%$ pertahun dari periode tahun 2007-2011. Faktor Populasi, tingkat pemahaman pengguna dan pertumbuhan kendaraan dianggap memiliki korelasi terhadap jumlah kecelakaan yang terjadi, namun berapa besar korelasi ini perlu diteliti lebih lanjut. Penelitian ini dilakukan di tiga kategori ukuran kota : kota kecil (kota Pariaman), kota sedang ( kota Payakumbuh) dan kota besar (kota Padang). Observasi di lapangan menunjukkan masih sangat rendahnya pemahaman pengguna kendaraan terhadap aturan lalu lintas dan etika berlalu lintas yang ada. Pengguna kendaraan yang tidak paham terhadap aturan dan etika berlalu lintas di kota Padang, Payakumbuh dan Pariaman masing-masingnya adalah $71 \%$, 86\%, dan $89 \%$. Pemodelan didapat dengan menggunakan metode model regresi linear berganda, sehingga diketahui korelasi antara faktor yang diteliti diatas dengan jumlah kecelakaan yang terjadi. Hasil penelitian menunjukkan bahwa terjadi korelasi yang berbeda pada setiap jenis ukuran kota. Jumlah kecelakaan di kota Padang memiliki korelasi dengan jumlah penduduk dan pemahaman pengguna kendaraan ; kota Payakumbuh berkorelasi dengan faktor jumlah penduduk ; sedangkan kota Pariaman berkorelasi hanya dengan pemahaman pengguna kendaraan saja. Dari hasil ini kemudian dipilih pemodelan yang paling tepat untuk masing-masing daerah, diantaranya : untuk kota padang adalah $Y=-3590.1417+0.0044 X_{1}+0.0013 X_{3}$, model Payakumbuh adalah $Y=-127.738+0.0019 X_{1}$, sedangkan Pariaman adalah $Y=26.8961+0.0119 X_{3}$, dan Sumatera Barat adalah $Y=18.2977+0.0002 X_{I}+0.0286 X_{2}+0.0009 X_{3}$. Selain itu juga banyak fakta-fakta lainnya yang ditemukan pada penelitian ini, seperti jumlah pemilik Surat Izin Mengemudi (SIM) yang mengikuti Ujian teori dan praktek.
\end{abstract}

Kata kunci : kecelakaan, lalulintas, tingkat pemahaman aturan lalulintas, pemodelan dan prediksi kecelakaan

\section{PENDAHUluan}

Jalan raya yang awalnya berfungsi memperlancar pergerakan manusia dan barang dari satu tempat ke tempat lain ternyata akhir-akhir ini justru menjadi sumber kecelakaan. Jalan sudah tidak aman. Menurut Organisasi Kesehatan Dunia (WHO), pada tahun 1998 tabrakan di jalan merupakan penyebab terbesar luka atau kematian dini (early death) pada pria antara umur 15 sampai $44 \mathrm{di}$ seluruh negara. Data yang tercatat di Badan Pusat Statistik menunjukkan bahwa jumlah kecelakaan yang terjadi tahun 2011 adalah sebanyak108.696 kecelakaan dengan perincian : 31.195 korban meninggal (meningkat 63,48\%)*, 35.285 luka berat (meningkat 56,97\%)*, 108.945 luka ringan (meningkat 34,70\%)* dan kurang lebih 217 trilyun rupiah kerugian materi (meningkat 37,39)*.

\footnotetext{
1 Mahasiswa Program Magister Jurusan Teknik Sipil Fakultas Teknik Universitas Andalas, donna.vermilion@gmail.com

2 Staf Pengajar Jurusan Teknik Sipil Fakultas Teknik Universitas Andalas, yossyafra@ft.unand.ac.id

3 Staf Pengajar Jurusan Teknik Sipil Fakultas Teknik Universitas Andalas, titi@ft.unand.ac.id

*) Dibanding tahun 2010
} 
Ada begitu banyak penyebab kecelakaan, mulai dari kondisi jalan raya, kurangnya sarana dan prasarana rambu-rambu lalu lintas, kurangnya armada kepolisian, hingga kondisi kendaraan yang kurang baik. Namun semua faktor tersebut hanya 6,48\% penyebab kecelakaan, sedangkan 93,52\% penyebab kecelakaan ternyata adalah faktor manusia(Tabel 2.1).

Provinsi Sumatera Barat terdiri dari tujuh kota ; Padang, Solok, Sawahlunto, Padang Panjang, Bukittingi, Payakumbuh dan Pariaman yang memiliki profil yang beragam dilihat dari variabel jumlah kecelakaan, jumlah penduduk, jumlah kendaraan dan pemahaman terhadap peraturan dan etika berlalu lintas. Sehingga perlu diteliti mana variabel yang paling menentukan angka kecelakaan.

\section{KECELAKAAN DAN FAKTOR PENYEBAB KECELAKAAN}

Yang dimaksud dengan kecelakaan lalu lintas berdasarkan ketentuan yang ditetapkan dalam pasal 93 Peraturan Pemerintah Nomor 43 tahun 1993 ayat 1 adalah:

"Suatu peristiwa dijalan yang tidak disangka-sangka dan tidak disengaja melibatkan kendaraan dengan atau tanpa pemakai jalan lainnya mengakibatkan korban manusia atau kerugian harta benda"

Berdasarkan penelitian yang pernah dilakukan sebelumnya, faktor penyebab kecelakaan dapat dikomposisikan dalam tabel 1 berikut :

Tabel 2.1 Faktor-faktor penyebab kecelakaan

\begin{tabular}{|l|l|c|}
\hline FAKTOR PENYEBAB & \multicolumn{1}{|c|}{ U R A I A N } & \% \\
\hline Pengemudi & $\begin{array}{l}\text { lengah, mengantuk, tidak terampil, lelah, mabuk, } \\
\text { kecepatan tinggi, tidak menjaga jarak, kesalahan pejalan } \\
\text { kaki, gangguan binatang }\end{array}$ & 93,52 \\
\hline Kendaraan & $\begin{array}{l}\text { ban pecah, kerusakan sistem rem, kerusakan sistem } \\
\text { kemudi, as/kopel lepas, sistem lampu tidak berfungsi }\end{array}$ & 2,76 \\
\hline J a l a n & $\begin{array}{l}\text { persimpangan, jalan sempit, akses yang tidak dikontrol/ } \\
\text { dikendalikan, marka jalan kurang/tidak jelas, tidak ada } \\
\text { rambu batas kecepatan, permukaan jalan licin }\end{array}$ & 3,23 \\
\hline Lingkungan & $\begin{array}{l}\text { lalu-lintas campuran antara kendaraan cepat dengan } \\
\text { kendaraan lambat, interaksi/campur antara kendaraan } \\
\text { dengan pejalan, pengawasan dan penegakan hukum } \\
\text { belum efektif, pelayanan gawatdarurat yang kurang } \\
\text { cepat. Cuaca: gelap, hujan, kabut, asap }\end{array}$ & 0,49 \\
\hline
\end{tabular}

Sumber: Direktorat Jenderal Perhubungan Darat - Dept.Perhubungan, 2006

Beberapa penelitian tentang kecelakaan juga pernah dilakukan sebelumnya, diantaranya adalah :

1. Indriani dan Indawati (2005),

Penelitian ini membuktikan adanya hubungan antara tingkat keparahan korban kecelakaan lalu lintas dengan jenis kendaraan dan waktu terjadinya kecelakaan

2. Ismail dan Jemain (2005)

Penelitian ini Menunjukkan adanya hubungan antara jumlah kecelakaan lalu lintas dengan jenis kelamin korban kecelakaan, umur kendaraan, dan kawasan terjadinya kecelakaan.

3. EE Yulipriyono (2003)

Penelitian ini menunjukkan adanya Pengaruh Banyaknya Lajur Terhadap Jumlah Kecelakaan 


\section{METODOLOGI PENELITIAN}

Dari tujuh kota yang ada di Sumatera Barat dipilih 3 kota yang mewakili . Pemilihan kota didasarkan pada kategori kota, masing-masing adalah 1 kota besar, 1 kota sedang dan 1 kota kecil (klasifikasi berdasarkan Peraturan Pemerintah Republik Indonesia nomor 26 Tahun 2008 tentang Rencana Tata Ruang Wilayah Nasional), Sehingga lokasi yang dipilih untuk penelitian adalah :

Tabel 2.1 Kategori ukuran kota daerah penelitian

\begin{tabular}{|l|l|l|}
\hline Nama Kota & Jumlah Penduduk & Kategori \\
\hline Padang & 847567 & Kota Besar \\
\hline Payakumbuh & 119031 & Kota Sedang \\
\hline Pariaman & 80201 & Kota Kecil \\
\hline
\end{tabular}

Sedangkan pengolahan data dilakukan dengan cara berikut :
a. Uji Korelasi
b. Uji Multikolinearitas
c. Analisa Regresi

\section{PEMBAHASAN}

\subsection{Data Sekunder}

a. Data kecelakaan

Jumlah kecelakaan dari tahun 2007-2011 di Kota Padang, Payakumbuh dan Pariaman diperlihatkan oleh gambar 4.1 berikut ini :

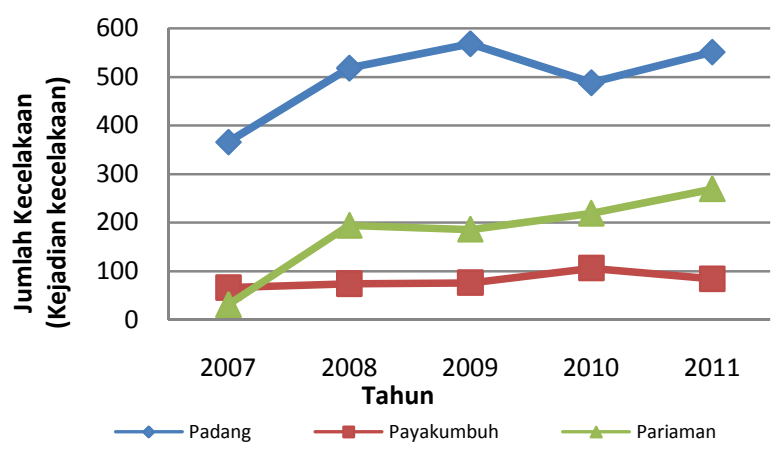

Gambar 4.1 Jumlah kecelakaan kota Padang, Payakumbuh dan Pariaman tahun 2007-2011 (Sumber : hasil analisa data BPS, 2013)

Jika dilihat dari gambar 4.1, jumlah kecelakaan setiap tahunnya cenderung meningkat (catatan : bahwa angka ini hanya angka kecelakaan yang terdata, tanpa mempertimbangkan kecelakaan yang tidak tercatat sebagai data kecelakaan).

b. Data jumlah Penduduk

Jumlah Penduduk dari tahun 2007-2011 adalah sebagai berikut : 


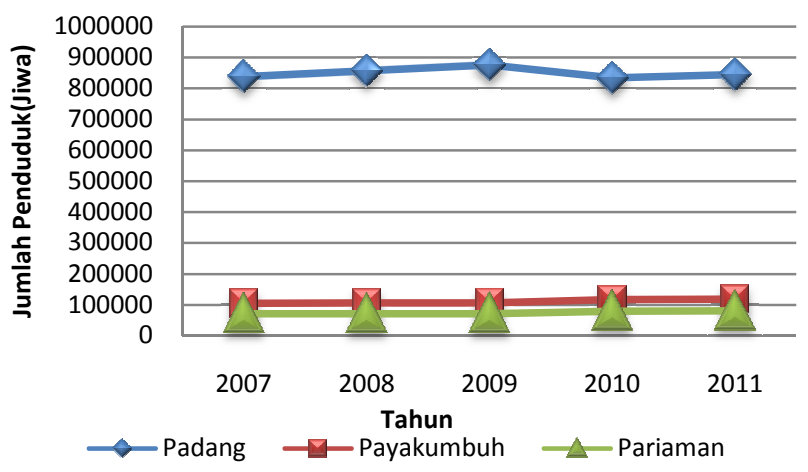

Gambar 4.2 Jumlah penduduk kota Padang, Payakumbuh dan Pariaman tahun 2007-2011

(Sumber : Hasil analisa data BPS, 2013)

Dari gambar 4.2 terlihat bahwa peningkatan jumlah penduduk paling tinggi mencapai $11,76 \%$ terjadi di kota pariaman pada tahun 2011.

c. Data kepadatan penduduk

Satu lagi variabel yang dianggap memiliki korelasi terhadap angka kecelakaan adalah kepadatan penduduk, dengan asumsi sementara bahwa semakin padat penduduk suatu wilayah maka tingkat kecelakaannya juga akan semakin tinggi atau sebaliknya, namun untuk membuktikan asumsi ini masih harus dilakukan uji korelasi. Berikut grafik kepadatan penduduk kota Padang, Payakumbuh dan Pariaman :

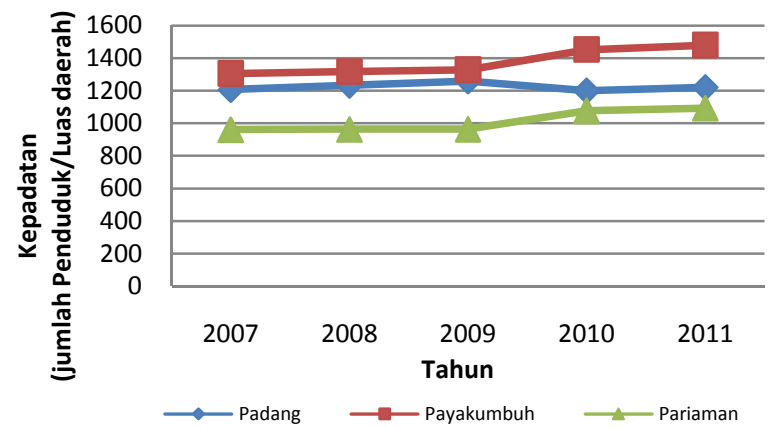

Gambar 4.3 Kepadatan penduduk kota Padang, Payakumbuh dan Pariaman tahun 2007-2011

(Sumber ; Hasil analisa data BPS, 2013)

\subsection{Data Primer}

Berikut adalah hasil yang didapat dari pengolahan data primer :

a. Hasil Survey Kepemilikan SIM, Pemilik SIM yang mengikuti Ujian dan Pengetahuan Pemilik kendaraan tentang buku etika berlalu lintas

Dari gambar 4.4 dan 4.5 diketahui bahwa masih ada (11\%) pengguna kendaraan tidak memiliki SIM, ini menandakan bahwa masih ada pelangaran Undang-Undang. Dan setelah dianalisa lagi, terlihat bahwa $68 \%$ pengguna kendaraan ternyata tidak mengikuti ujian teori dan praktek SIM. Dan $83 \%$ dari pengguna kendaraan yang di survey justru sama sekali tidak pernah tahu tentang buku Etika berlalu lintas, sedangkan $17 \%$ nya adalah jumlah untuk yang pernah melihat/membaca. 


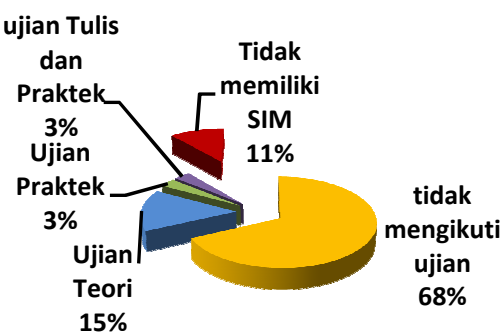

Gambar 4.4 Persentase kepemilikan SIM di kota Padang (Sumber : Hasil analisa survey, 2013)

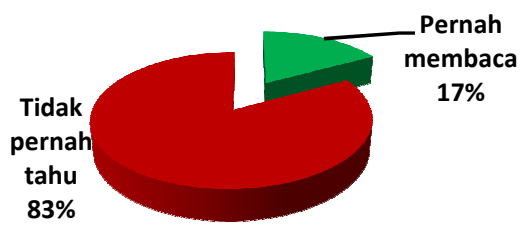

Gambar 4.5 Persentase pemilik kendaraan yang membaca buku etika berlalulintas di kota Padang (Sumber : Hasil analisa survey, 2013)

Di kota Payakumbuh (gambar 4.6 dan 4.7), jumlah pengguna kendaraan yang tidak memiliki SIM lebih banyak dan mencapai angka 34\%, 33\% ternyata tidak mengikuti ujian teori dan praktek, $20 \%$ hanya mengikuti ujian teori, $2 \%$ hanya mengikuti ujian praktek dan hanya $11 \%$ yang mengikuti ujian teori dan praktek. Sementara tentang buku etika berlalu lintas $77 \%$ menyatakan tidak mengetahui sama sekali dan $23 \%$ menyatakan pernah melihat atau membaca buku ini.

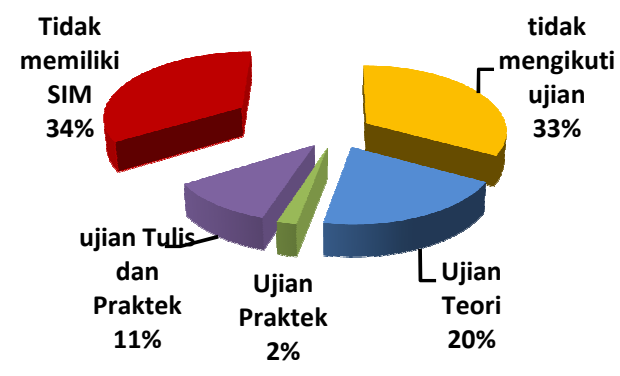

Gambar 4.6 Persentase kepemilikan SIM di kota Payakumbuh

(Sumber : Hasil analisa Survey, 2013)

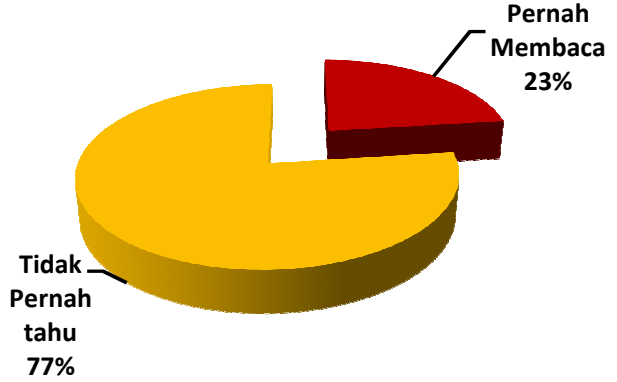

Gambar 4.7 Persentase pemilik kendaraan yang membaca buku etika berlalulintas di kota Payakumbuh

(Sumber : Hasil Analisa Survey, 2013)

Penelitian di kota Pariaman menunjukkan bahwa 50\% responden ternyata tidak memiliki SIM. Selanjutnya, $28 \%$ tidak mengikuti ujian teori dan praktek, $12 \%$ hanya mengikuti ujian teori, $2 \%$ hanya mengikuti ujian praktek dan hanya $8 \%$ mengikuti ujian teori dan praktek. Sedangkan yang pernah membaca atau melihat buku etika berlalu lintas hanya 11\% (Gambar 4.8 dan 4.9)

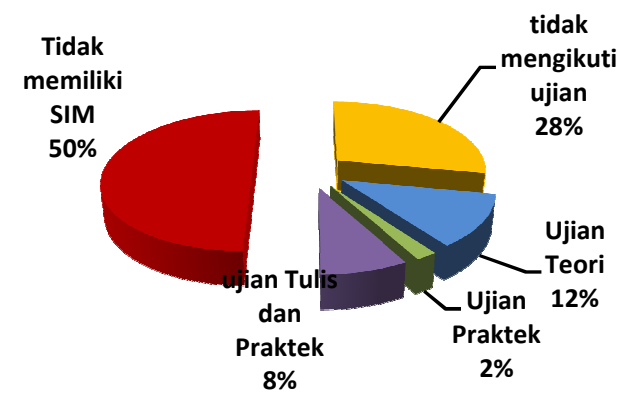

Gambar 4.8 Persentase kepemilikan SIM di Kota Pariaman (Sumber : Hasil analisa Survey, 2013)

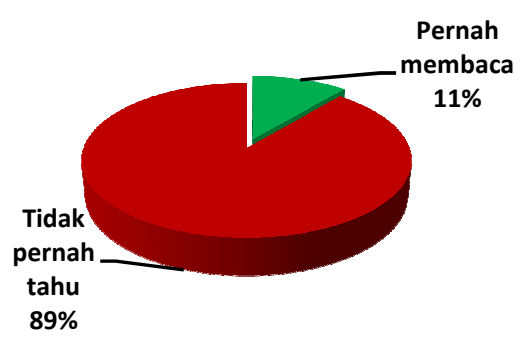

Gambar 4.9 Persentase pemilik kendaraan yang membaca buku etika berlalu lintas di kota Pariaman 
b. Pemahaman terhadap peraturan lalulintas

Sepuluh pertanyaan diajukan kepada masing-masing responden untuk mengetahui tingkat pemahaman pengguna kendaraan, dan hasil penelitian tentang tingkat pemahaman dapat dilihat pada gambar 4.10 berikut.

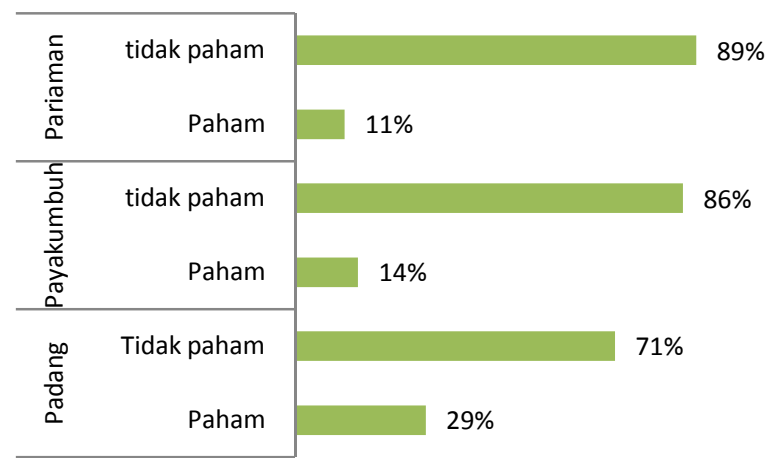

Gambar 4.10 Persentase tingkat pemahaman terhadap peraturan lalulintas

(Sumber : hasil analisa Survey, 2013)

Standar kepahaman sesuai dengan Peraturan Kepala Polisi Republik Indonesia no.9 tahun 2012 yang menyatakan bahwa standar kompetensi atau kepahaman terhadap peraturan lalu lintas adalah yang mampu menjawab soal ujian teori SIM minimal $70 \%$ dari total soal yang diberikan.

\subsection{Pengolahan Data Pemahaman}

Data yang akan dihasilkan dari data pemahaman adalah jumlah pengendara yang dianggap tidak paham terhadap peraturan dan etika berlalu lintas, perhitungan jumlah tersebut akan didapat dengan cara :

\section{Data jumlah kendaraan $\mathrm{x} \%$ tidak paham}

Dengan asumsi bahwa tingkat pemahaman pengendara tidak berubah dari tahun 2008-2009 karena memang pelaksanaan Undang-Undang no.22 th 2009 yang tidak maksimal, terlihat dengan tidak berkurangnya angka kecelakaan sejak tahun $2009-2012$.

\subsection{Pemodelan Kecelakaan}

Hasil analisa regresi dan uji statistik untuk memilih pemodelan terbaik masing-masing kota dan provinsi Sumatera Barat (dengan Level of confidence 85\% ) adalah sebagai berikut :
a. Kota Padang :$$
Y=-3590.1417+0.0044 X_{1}+0.0013 X_{3}
$$
b. Kota Payakumbuh :$$
Y=-127.738+0.0019 X_{1}
$$
c. Kota Pariaman :

$$
Y=26.8961+0.01191 X_{3}
$$
d. Sumatera Barat :

$$
Y=18.2977+0.0002 X_{1}+0.0286 X_{2}+0.0009 X_{3}
$$


Keterangan :

$X_{l}=$ jumlah penduduk

$X_{2}=$ kepadatan penduduk

$X_{3}=$ jumlah yang tidak paham aturan

\subsection{Prediksi Kecelakaan}

Dengan menggunakan pemodelan terpilih hasil uji statistik maka prediksi kecelakaan hingga tahun 2021 dapat dilakukan. Berdasarkan persamaan (1) diketahui bahwa variabel yang mempengaruhi kecelakaan adalah jumlah penduduk dan jumlah yang tidak paham aturan, sehingga dapat diprediksi kecelakaan di kota Padang pada tahun 2016 adalah 779 kecelakaan dan 994 kecelakaan diprediksi akan terjadi di tahun 2021 ; berdasarkan persamaan (2) variabel yang mempengaruhi kecelakaan adalah jumlah penduduk, dan diperhitungkan bahwa ditahun 2016 diprediksi akan terjadi 133 kecelakaan di kota Payakumbuh dan 176 kecelakaan ditahun 2021 ; persamaan (3) menunjukkan bahwa variabel yang mempenyai pengaruh terhadap kecelakaan adalah jumlah pengguna kendaraan yang tidak paham aturan dan prediksi kecelakaan di kota Pariaman sebanyak 460 kecelakaan ditahun 20176 dan 660 kecelakaan ditahun 2021 ; sedangkan persamaan (4) menghasilkan perhitungan prediksi kecelakaan ditahun 2016 sebanyak 2075 kecelakaan dan tahun 2021 sebanyak 2494 kecelakaan dan variabel yang mempengaruhi kecelakaannya adalah jumlah penduduk, kepadatan penduduk dan jumlah yang tidak paham aturan.

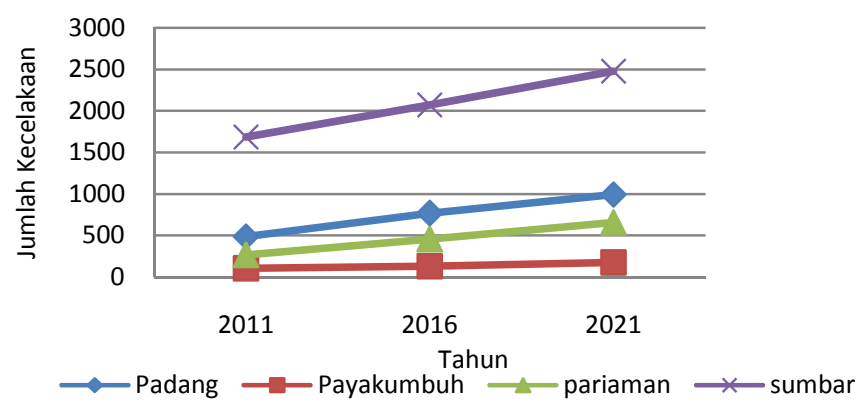

Gambar 4.11 Prediksi kecelakaaan di kota Padang, Payakumbuh, Pariaman dan Sumatera Barat tahun 2016 dan 2021 (Sumber ; Hasil Analisa Data, 2013)

\subsection{Analisa Pengaruh Kerapatan Kendaraan Terhadap Kecelakaan}

Gambar 4.12 memperlihatkan pengaruh antara kerapatan kendaraan (kumlah kendaraan/jumlah penduduk) dengan jumlah kecelakaan (data BPS tahun 2007-2011) menunjukkan bahwa korelasi paling tinggi antara jumlah kecelakaan dan kerapatan kendaraan terhadap jumlah penduduk diperlihatkan oleh kota Pariaman dengan nilai $\mathrm{R}^{2}=0.97$. 


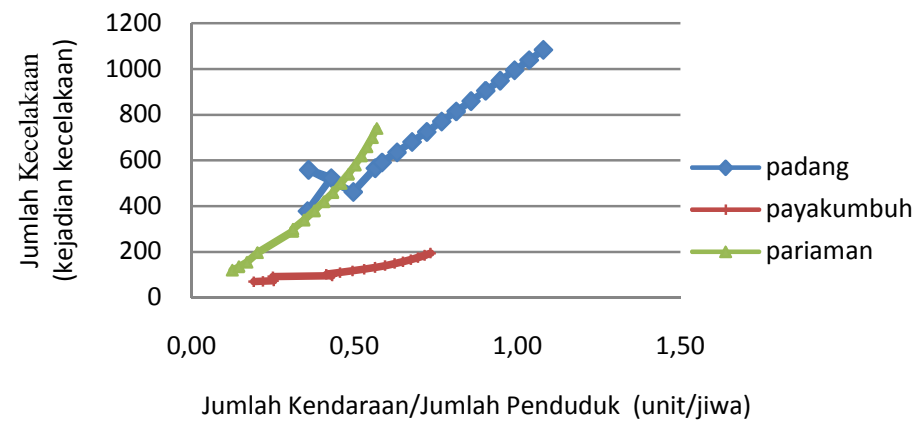

Gambar 4.12 Analisa pengaruh kerapatan kendaraan terhadap jumlah kecelakaan (Sumber ; Hasil Analisa Data, 2013)

Gambar 4.12 menunjukkan bahwa prediksi jumlah kecelakaan jika ditinjau dari kerapatan kendaraan (jumlah kendaraan/jumlah penduduk) kota Pariaman memperlihatkan pola peningkatan yang lebih tinggi dari kota lainnya.

\subsection{Analisa Pengaruh Peningkatan Kepahaman Terhadap Kecelakaan}

Dari hasil penelitian terlihat bahwa kota yang jumlah kecelakaannya dipengaruhi oleh faktor kepamahaman terhadap aturan dan etika berlalulintas adalah kota Padang dan Pariaman, sementara kota Payakumbuh tidak menunjukkan adanya hubungan antara tingkat kepahaman dengan kecelakaan, hal ini bisa disebabkan karena jumlah kendaraan yang ada di kota Payakumbuh belum terlalu banyak jika dibandingkan dengan panjang jalan yang ada.

Jika tingkat pemahaman di kota Padang dan Pariaman dapat ditingkatkan, dengan kata lain berkurangnya ketidakpahaman, maka jumlah angka kecelakaan akan dapat diturunkan. Gambar 4.13 menunjukkan jika ketidakpahaman bisa diturunkan hingga $70 \%$ maka akan menurunkan tingkat kecelakaan sebesar 74,73\% dari 566 menjadi 143 kecelakaan di kota Padang. Sedangkan untuk kota Pariaman dengan penurunan ketidakpahaman sebesar $70 \%$ akan menurunkan tingkat kecelakaan sebesar 90,69\% dari 290 kecelakaan menjadi 27 kecelakaan.

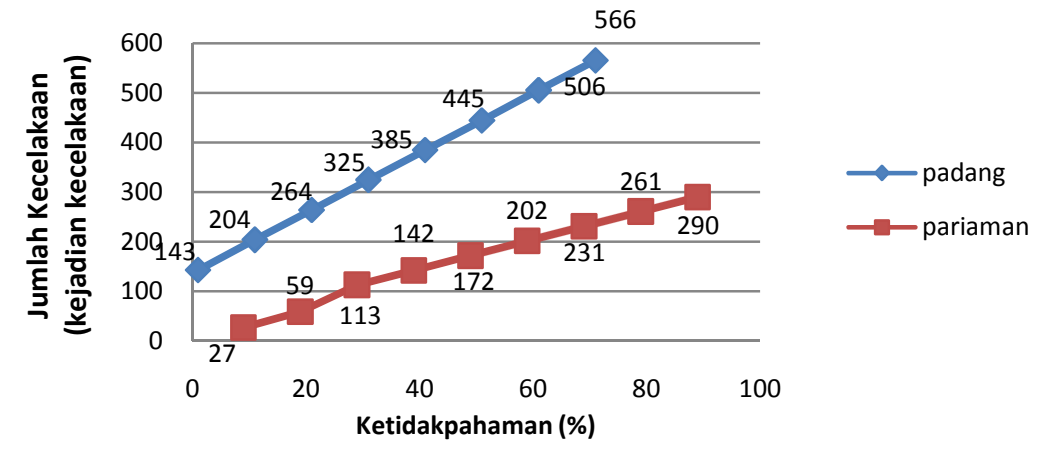

Gambar 4.13 Analisa prediksi pengaruh berkurangnya ketidakpahaman terhadap jumlah kecelakaan

(Sumber ; hasil analisa data, 2013)

\section{KESIMPULAN DAN SARAN}


Dari penelitian yang dilakukan dapat disimpulkan beberapa hal, diantaranya :

1. Penelitian di kota Padang memperlihatkan adanya korelasi antara variabel jumlah penduduk dan jumlah pengguna kendaraan yang tidak paham aturan dengan jumlah kecelakaan.

2. Penelitian di kota Payakumbuh menunjukkan bahwa diantara tiga variabel 'jumlah penduduk, kepadatan penduduk, dan pemahaman terhadap peraturan dan etika berlalu lintas', hanya variabel jumlah penduduk yang memiliki korelasi dengan jumlah kecelakaan.

3. Penelitian di kota Pariaman memperlihatkan adanya korelasi antara jumlah kecelakaan dengan pemahaman.

4. Penelitian di Sumatera Barat memperlihatkan adanya korelasi antara variabel jumlah penduduk, kepadatan penduduk, dan pemahaman terhadap peraturan dan etika berlalu lintas dengan jumlah kecelakaan.

5. Hasil penelitian juga menunjukkan bahwa masih sangat rendahnya pemahaman pengguna kendaraan di Sumatera Barat terhadap aturan dan etika berlalulintas. 82\% dari pengguna kendaraan ternyata tidak memahami aturan dan etika berlalu lintas..

Sedangkan saran yang dapat diberikan untuk perbaikan dan penelitian selanjutnya antara lain :

1. Perlu penelitian lebih lanjut terhadap pengaruh pengawasan dan pelaksanaan peraturan pembuatan SIM sesuai undang-undang(dengan ujian teori, Praktek dan tes Kesehatan) terhadap pemahaman pengguna kendaraan tentang aturan dan etika berlalu lintas dan kemampuan penerapan/aplikasi aturan dan etika berlalu lintas

2. Perlunya penelitian lebih lanjut yang memperbandingkan tingkat kepahaman pengguna kendaraan di kota yang penerapan peraturan lalu lintasya 'baik' dengan kota yang penerapannya 'kurang baik', sekaligus menganalisa jumlah kencelakaan masing-masing karakteristik kota

3. Perlunya penelitian lebih lanjut yang menganalisa kecelakaan berdasarkan pertumbuhan kendaraannya dan panjang jalan di masing-masing kota serta pola penyebaran kepadatan penduduknya.

4. Perlunya penelitian lebih lanjut terhadap jumlah pemilik SIM yang tercatat di Kepolisian masing-masing kota dan persantase (\%) pemilik SIM yang mengerti dan paham terhadap aturan dan etika berlalu lintas dan diperbandingkan dengan jumlah kecelakaan yang pernah dialami masing-masing.

5. Agar didapat pemodelan untuk memprediksi kecelakaan yang lebih baik maka sebaiknya diperhatikan akurasi data yang diperoleh.

\section{DAFTAR KEPUSTAKAAN}

Badan Pusat Statistik (2012), Sumatera Barat dalam angka, Badan Pusat Statistik, Sumatera Barat.

Badan Pusat Statistik. (2012), Padang dalam Angka, Badan Pusat Statistik, Padang

Badan Pusat Statistik. (2012), Bukittinggi dalam Angka, Badan Pusat Statistik, Bukittinggi.

Badan Pusat Statistik. 2012 , Solok dalam Angka, Badan Pusat Statistik, Solok.

Badan Pusat Statistik. 2012 e , Sawahlunto dalam Angka, Badan Pusat Statistik, Sawahlunto.

Badan Pusat Statistik. 2012 ${ }^{\mathrm{f}}$, Padang Panjang dalam Angka, Badan Pusat Statistik, Padang Panjang.

Badan Pusat Statistik. 2012 ${ }^{\mathrm{g}}$, Payakumbuh dalam Angka, Badan Pusat Statistik, Payakumbuh.

egienews.blogspot.com. 2013, Uji Asumsi Klasik Regresi Data Panel Dengan Eviews (Multikolinearitas), Part 7, diakses pada tanggal 13 Agustus 2013 http://egienews.blogspot.com/2013/06/part-7-uji-asumsi-klasik-regresi-data.html

Kartika, Metta. 2009, Analisis Faktor Penyebab Kecelakaan Lalu Lintas Pada Pengendara Sepeda Motor di Wilayah Depok, Skripsi, Universitas Indonesia, di akses pada tanggal 6 Maret 2013 http://lontar.ui.ac.id/file?file=digital/125831-S-5849-Analisis faktor-HA.pdf

Martadiputra, Bambang Avip Priatna. 2008, Analisis Regresi Menggunakan SPSS Versi 15, Jurnal, Universitas Pendidikan Indonesia, diakses pada tanggal 13 Agustus 2013 
Cut Dona Kordelia ${ }^{1}$, Yossyafra ${ }^{2}$, Titi Kurniati ${ }^{3}$

http://file.upi.edu/Direktori/FPMIPA/JUR._PEND._MATEMATIKA/196412051990031-

BAMBANG_AVIP PRIATNA M/ANALISIS REGRESI.pdf

Ngada.org. 2012, Peraturan Kepala Kepolisian Negara Republik Indonesia Nomor 9 Tahun 2012 Tentang

Surat Izin Mengemudi, diakses tanggal 6 Maret 2013

http://ngada.org/bn279-2012.htm

Roads and Traffic Authority.2010, Heavy Vehicle Drivers' Handbook, Roads Traffic Authorithy, Australia.

Roads and Traffic Authority.2010, Motorcycle Riders' Handbook, Roads Traffic Authorithy, Australia.

Roads and Traffic Authority.2010, A Guide to DART, Roads Traffic Authorithy, Australia.

Sinaga, Mailani Kristin. 2012, Gambaran Faktor-Faktor Penyebab Kecelakaan Lalu Lintas Di Kota Medan Tahun 2010, Skripsi, Universitas Sumatera Utara, di akses pada tanggal 6 Maret 2013, http://repository.usu.ac.id/handle/123456789/33552 